\title{
Sorafenib prevents human retinal pigment epithelium cells from light-induced overexpression of VEGF, PDGF and PIGF
}

\author{
M Kernt, A S Neubauer, R G Liegl, C Hirneiss, C S Alge, A Wolf, M W Ulbig, \\ A Kampik
}

Department of Ophthalmology, Ludwig Maximilian University, Munich, Germany

\section{Correspondence to}

Dr Marcus Kernt, Department of Ophthalmology,

Ludwig-Maximilians-University, Mathilden St 8, Munich 80336, Germany; marcus.kernt@med. uni-muenchen.de

Accepted 16 May 2010

\begin{abstract}
Background Cumulative light exposure is significantly associated with progression of age-related macular degeneration (AMD). Inhibition of vascular endothelial growth factor is the main target of current antiangiogenic treatment strategies in AMD. However, other growth factors, such as platelet-derived growth factor (PDGF) and placenta growth factor (PIGF), have a substantial impact on development of AMD. Previous reports indicate that sorafenib, an oral multikinase inhibitor, might have beneficial effects on exudative AMD. This study investigates the effects of sorafenib on lightinduced overexpression of growth factors in human retinal pigment epithelial (RPE) cells.
\end{abstract}

Methods Primary human RPE cells were exposed to white light and incubated with sorafenib. Viability, expression, and secretion of VEGF-A, PDGF-BB, and PIGF and their mRNA were determined by reverse transcription-polymerase chain reactions, immunohistochemistry and enzyme-linked immunosorbent assays.

Results Light exposure decreased cell viability and increased expression and secretion of VEGF-A, PDGF-BB and PIGF. These light-induced effects were significantly reduced when cells were treated with sorafenib at a dose of $1 \mu \mathrm{g} / \mathrm{ml}$.

Conclusion The results show that sorafenib has promising properties as a potential antiangiogenic treatment for AMD.

\section{INTRODUCTION}

Exudative age-related macular degeneration (AMD) is a leading cause of visual deterioration and legal blindness in people over the age of 60 in developed countries. ${ }^{1}$ Early stages of this disease are characterised by the formation of drusen and atrophic changes in the retinal pigment epithelium (RPE). ${ }^{1}$ With progression of the disease, $10 \%$ of patients develop 'wet' forms of $\mathrm{AMD}$ due to choroidal neovascularisation (CNV) that often leads to a rapid loss of vision. ${ }^{1}$ AMD is a multifactorial disease with several risk factors for development and progression, including ethnicity, gender, smoking, hypertension, genetics, diet and sunlight exposure. $^{1-4}$

$\mathrm{CNV}$ in the macular region often results in significant loss of central vision and high-resolution visual acuity, and is the fundamental pathophysiological process underlying this disease. ${ }^{5}{ }^{6}$ Without treatment, AMD can lead to irreversible loss of the ability to read, recognise faces, and drive. ${ }^{5} 6$
Upregulation of vascular endothelial growth factor (VEGF) is a major critical event in the development of $\mathrm{CNV}^{7}$ Therefore, inhibition of VEGF is the main target of the currently used antiangiogenic agents in the treatment of $\mathrm{AMD}{ }^{8}$ The mechanism of action of these VEGF inhibitors (eg, bevacizumab and ranibizumab) is blocking VEGF in the extracellular space and thereby preventing access to its receptor. ${ }^{9}$ Studies have demonstrated that treatment of AMD with VEGF inhibitors is safe and effective. ${ }^{10-12}$ However, major prospective randomised trials revealed that despite an improvement in visual acuity, the neovascular tissue typically does not regress with VEGF inhibition alone, and without continuous treatment often reprogression occurs. ${ }^{10} 11$ The reason for this lack of sustained effect might be due to redundant pathways. Previous studies indicated that several angiogenic growth factors, including plateletderived growth factor (PDGF) and placenta growth factor (PIGF), are overexpressed in the vitreous and retinas in proliferative retinal disease and play a crucial role in the development and progression of AMD. ${ }^{13-16}$ The reason for this could be that other molecular pathways remain active, and binding VEGF in the extracellular space alone might have only limited effect on neovascular tissue. In addition, inhibition of a single molecule could induce a compensatory increase in stimulatory increase of alternative pathways.

Sorafenib (Nexavar, BAY 43-9006) is an oral multikinase inhibitor, approved for the treatment of several forms of cancer. ${ }^{17}$ Previous case reports indicate that sorafenib, alone or in combination with other angiostatic drugs, might have a beneficial effect on exudative AMD. ${ }^{18} 19$

This study was designed to investigate the effect of sorafenib on light-induced growth factor expression in the RPE, which plays a key role in the development and progression of AMD. ${ }^{1}$ Therefore, we exposed primary human RPE cells to wide-band white light (spectral range 400-700 nm). Cells were treated with sorafenib and the drug's effects on viability of the cells after light exposure was investigated. Expression of VEGF-A, PDGF-BB and PIGF was determined.

\section{METHODS}

\section{Materials}

Sorafenib (Nexavar, BAY 43-9006 [N-(3-trifluoromethyl-4-chlorophenyl)-N-(4-(2-methylcarbamoyl pyridin-4-yl)oxyphenyl)urea]) was dissolved in 100\% dimethyl sulfoxide (DMSO; Sigma, St Louis, 
Missouri) and diluted with DMSO, and the cell culture medium to the desired concentration with a final DMSO concentration of $0.1 \%$ for in vitro studies. DMSO was added to cultures at $0.1 \%(\mathrm{v} / \mathrm{v})$ as a solvent control.

\section{Ethics}

The methods of securing human tissue were humane, included proper consent and approval, complied with the Declaration of Helsinki and were approved by the local ethics committee.

\section{Human RPE cell culture}

Primary RPE cells from four human donors (48, 52, 56 and 74 years old, obtained $3-10 \mathrm{~h}$ postmortem) without any history of eye disease were obtained from the Eye Bank of Ludwig Maximilian University and were prepared as previously described. $^{20}$ Dulbecco modified Eagle medium (DMEM; Biochrom, Berlin, Germany) supplemented with 10\% fetal calf serum (FCS; Biochrom) was used as the cell-culture medium. An increased accumulation of lipofuscin is a common characteristic of ageing RPE cells in vivo, and lipofuscin is known to act as a photosensitiser. It has been implicated to play a certain role in the development and progression of $\mathrm{AMD} .^{21-23}$ To investigate the effects of white light on RPEs growth factor expression, we used primary RPE cells of passages 2 and 3 for our experiments. All investigated RPE cell cultures presented intracellular pigmented granules in phase-contrast microscopy. These granules contain, besides melanin and other pigments, a certain amount of lipofuscin. This characteristic disappears when RPE cells are cultured for long-term periods. ${ }^{24-26}$

\section{Cell culture treatment}

For all cell-culture experiments, RPE cells were seeded in $35 \mathrm{~mm}$ tissue culture dishes and cultured on confluence in darkness. RPE cells were kept for $24 \mathrm{~h}$ in serum-free conditions. After the cells were washed with phosphate-buffered saline (PBS), they were illuminated for $60 \mathrm{~min}$. Directly after illumination, PBS was replaced with serum-free cell culture medium, and sorafenib was added with a final concentration of $1 \mu \mathrm{g} / \mathrm{ml}$.

\section{Illumination of cells}

A spot-light source (LC-8; Hamamatsu Photonics, Shizuoka, Japan) from a mercury-xenon lamp equipped with an optic fibre as the light guide (spectral range: $400-700 \mathrm{~nm}$ ) was used for illumination. The cell-culture medium was replaced with $\mathrm{PBS}$ just before illumination. The plastic cover of the illuminated cell culture well was removed, and the cells were illuminated from above. They were illuminated $\left(300 \mathrm{~mW} / \mathrm{cm}^{2}\right)$ for $60 \mathrm{~min}$. The illumination power and spectral range were measured with a spectrometer (C10083MD; Hamamatsu Photonics). Directly after illumination, PBS was replaced by serum-free cell culture medium, sorafenib was added with a final concentration of $1 \mu \mathrm{g} /$ $\mathrm{ml}$, and the cells were kept in darkness for another $24 \mathrm{~h}$. Then, the methylthiotetrazole (MTT) assay, ELISA for detection of growth factor concentrations in cell culture supernants, epifluorescence microscopy, phase-contrast microscopy and RNA isolation were performed.

\section{MTT assay}

The tetrazolium dye-reduction assay (MTT; 3-[4,5-dimethylthiazol-2-yl]-2,5-diphenyl tetrazolium bromide) was used to determine the cell survival rate. The MTT test, which is well established for the assessment of cell viability, was performed as described by Mosmann, ${ }^{27}$ with some modifications. The medium was removed, the cells were washed with PBS, and
$1000 \mathrm{ml}$ of MTT solution (1.5 $\mathrm{ml}$ MTT stock, $2 \mathrm{mg} / \mathrm{ml}$ in PBS, plus $28.5 \mathrm{ml}$ MEM) was added to each well. RPE cells were incubated at $37^{\circ} \mathrm{C}$ for $1 \mathrm{~h}$. The formazan crystals that formed were dissolved by the addition of $1000 \mathrm{ml}$ DMSO per well. Absorption was measured by a scanning multiwell spectrophotometer at $550 \mathrm{~nm}$ (Molecular Probes, Eugene, Oregon). The results were expressed as the mean percentage of proliferation in the control.

To investigate the effects of different sorafenib concentrations on RPE cell viability, cells were brought to confluence, kept under serum-free conditions for $24 \mathrm{~h}$ and then were treated with sorafenib concentrations of $0.5,1,1.25,2.5,5,7.5,10,12.5,15$, 25 and $50 \mu \mathrm{g} / \mathrm{ml}$ for another $24 \mathrm{~h}$. Then, the MTT assay was performed. To investigate the effects of sorafenib on RPE cell viability after light exposure, cells were illuminated and treated as described above. At $24 \mathrm{~h}$ after illumination, the MTT assay was performed.

The experiments were performed in triplicate and repeated three times. The control cells were RPE cells of the same passage; they were kept in darkness, without exposure to any radiation.

Detection of VEGF-A, PDGF-BB and PIGF secretion by RPE cells $\mathrm{RPE}$ cell cultures were grown to confluence and treated as described. Levels of VEGF-A, PDGF-BB and PIGF in the culture supernatants were determined by ELISA. The supernatants were collected after $24 \mathrm{~h}$, and the levels of VEGF-A, PDGF-BB and PIGF were quantified using a VEGF-A, PDGF-BB or PIGF Quantikine ELISA Assay Kit ( $R$ \& D Systems, Minneapolis, Minnesota) according to the manufacturer's instructions.

\section{RNA isolation and real-time PCR}

Total RNA was isolated from $10 \mathrm{~cm}$ Petri dishes by the guanidium thiocyanate-phenol-chloroform extraction method (Stratagene, Heidelberg, Germany). The structural integrity of the RNA samples was confirmed by electrophoresis in $1 \%$ Trisacetate-EDTA agarose gels. The yield and purity were determined photometrically (BioPhotometer; Eppendorf, Hamburg, Germany). Real-time PCR enables quantitative detection of small amounts of mRNA. After the usual isolation of mRNA, this mRNA was transferred to complementary DNA (cDNA) through reverse transcriptase (RT). This $c D N A$ was then used for the specific PCR. Quantification of VEGF-A, PDGF-BB and PIGF mRNA was performed with specific primers with a LightCycler instrument (LightCycler System; Roche Diagnostics, Mannheim, Germany). Primers and probes were detected with ProbeFinder 2.04. All primers and probes were designed to cross intron/exon boundaries to avoid amplification of genomic DNA. All PCR products were sequenced to ensure product validity. Each $14 \mu \mathrm{l}$ reaction volume contained $1 \times$ FastStart DNA Master Hybridisation Probes Mix (Roche Diagnostics), $4 \mathrm{mM} \mathrm{MgCl}$, $0.5 \mathrm{mM}$ of each primer, $0.2 \mathrm{mM}$ TaqMan probe and $2 \mu \mathrm{l} \mathrm{cDNA}$.

The amplification signals were detected in real time, which allowed accurate quantification of the amounts of the initial RNA template, because the system can select signals easily during the exponential amplification phase of PCR. The cDNA of RPE cells, either after incubation with sorafenib or untreated and then exposed to light, was amplified with specific primers for 40 cycles. Two oligonucleotides with different labelled fluorophores were hybridised to the amplified fragment during the annealing phase. When the two probes came into close proximity, fluorescence resonance energy transfer (FRET) developed between the two fluorophores. The emitted fluorescence was then measured by the LightCycler instrument. Hybridisation probes were displaced during the extension step. Depending on 
Table 1 Primers used for RT-PCR

\begin{tabular}{llllll}
\hline Target & Length & Position & AT $\left({ }^{\circ} \mathbf{C}\right)$ & Percentage GC & Sequence \\
\hline Vascular endothelial growth factor-A & 18 & $1540-1557$ & 60 & 56 & tgcccgctgctgtctaat \\
& 18 & $1592-1609$ & 60 & 61 & tctccgctctgagcaagg \\
Placenta growth factor & 18 & $335-352$ & 60 & 61 & ggctgttcccttgcttcc \\
Platelet-derived growth factor-BB & 18 & $395-412$ & 59 & 61 & cagacaaggcccactgct \\
& 18 & $1108-1125$ & 60 & 56 & tgatctccaacgcctgct \\
& 20 & $1156-1175$ & 59 & 50 & tcatgttcaggtccaactcg \\
\hline
\end{tabular}

AT, adenine-thymidine; GC, guanine-cytosine.

the initial concentration of target genes, the signal intensity increased in different cycles, and these cycles were used as the crossing point. The standard curve was made with three different probes of untreated RPE cells. For normalisation of differences in the amount of total RNA added to each reaction, $18 \mathrm{~S}$ rRNA was simultaneously processed in the same sample as an internal control. The level of VEGF-A, PDGF-BB and PIGF mRNA was determined as the relative ratio (RR), which was calculated by dividing the level of VEGF-A, PDGF-BB and PIGF mRNA by the level of the 18S rRNA housekeeping gene in the same samples. The ratios are expressed as decimals. All experiments were performed at least in triplicate and repeated three times. Table 1 lists the primers used for RT-PCR.

\section{Immunohistochemistry of RPE cell cultures}

Cultured RPE cells were grown on microscope slides and treated as described above. After incubation, cells were fixed with 4\% phosphonoformic acid (PFA) for $15 \mathrm{~min}$ and subsequently washed twice with PBS containing $0.1 \%$ Triton X-100. Primary incubation of all samples was performed with a mouse antihuman VEGF-A antibody (Santa Cruz Biotechnology, Santa Cruz, California), a mouse antihuman PDGF-B antibody (Santa Cruz Biotechnology) and a goat antihuman PlGF antibody (Santa Cruz Biotechnology), diluted 1:200 in PBS for $4 \mathrm{~h}$ at room temperature. After washing three times, the culture dishes and sections were further processed with a Texas Red-conjugated rabbit antimouse secondary antibody or a fluorescein-conjugated rabbit antigoat secondary antibody (diluted 1:500 in PBS; Santa Cruz Biotechnology) for $1 \mathrm{~h}$ at room temperature, rinsed in PBS and mounted with Kaiser's glycerine jelly (Merck, Darmstadt, Germany). Slides were investigated with a Zeiss Axio Imager fluorescence microscope (Carl Zeiss AG, Oberkochen, Germany). All experiments were performed at least nine times with RPE cells from three different cell cultures.

\section{Statistical evaluation}

All data were analysed with SPSS 13.0 for Windows (SPSS, Chicago, Illinois). For all statistical tests, $\mathrm{p}<0.05$ was considered significant. Results of the MTT assay are presented as mean (SD) units of absorbance. Ten individual samples per group were measured in triplicate. The Mann-Whitney test was used. Results from VEGF-A, PDGF-BB and PIGF ELISA are presented as mean (SD) ratios of each tested probe, which were normalised to the control. Results of the RT-PCR are presented as mean (SD) ratios of the investigated mRNA and $18 \mathrm{~S}$ rRNA. Again, Mann-Whitney testing was applied; all experiments were performed at least in triplicate and repeated three times.

\section{RESULTS}

\section{Viability of cells}

Testing concentrations of sorafenib in primary RPE cells

No gross abnormalities, such as abnormal shape and appearance, cellular lysis, cellular death or other abnormalities, were detected with phase-contrast microscopy up to a concentration of
$12.5 \mu \mathrm{g} / \mathrm{ml}$ sorafenib in primary RPE cells after $24 \mathrm{~h}$ treatment. The number of cells counted in phase-contrast microscopy correlated well with the quantitative results of the MTT test.

\section{MTT assay}

Sorafenib showed no significant toxic effects in the investigated RPE cell cultures ( $24 \mathrm{~h}$ exposure) at concentrations between 0.5 and $12.5 \mu \mathrm{g} / \mathrm{ml}$. No significant decrease (Wilcoxon with $\alpha$ correction for multiple testing) in cellular viability was detected with RPE cells compared with the control. Concentrations of sorafenib between 15 and $25 \mu \mathrm{g} / \mathrm{ml}$ showed an increasing reduction in cell viability, but still $>60 \%$ of the cells revealed activity. At a sorafenib concentration of $50 \mu \mathrm{g} / \mathrm{ml}$, a more rapid, dose-dependent and significant reduction in viability was seen (figure 1 ).

Testing the effects of sorafenib on viability of RPE cells after light exposure

When cells were illuminated with unfiltered white light $\left(300 \mathrm{~mW} / \mathrm{cm}^{2}\right)$ for $60 \mathrm{~min}$, a significant reduction in RPE cell viability was detected (figure 2 ). In contrast, cells treated with sorafenib, $1 \mu \mathrm{g} / \mathrm{ml}$, immediately after illumination showed a significantly smaller less decrease in viability compared with cells that were not treated with sorafenib (figure 2).

\section{Expression of VEGF-A, PDGF-B and PIGF mRNA}

VEGF-A, PDGF-BB and PIGF mRNA expression was detected in every sample. All detected mRNA levels of VEGF-A, PDGF-BB and PIGF were normalised to those of $18 \mathrm{~S}$ rRNA; the values are expressed as the RR of VEGF-A/18S, PDGF-BB/18S or PIGF/18S. Illumination with white light for $60 \mathrm{~min}$ led to a significant

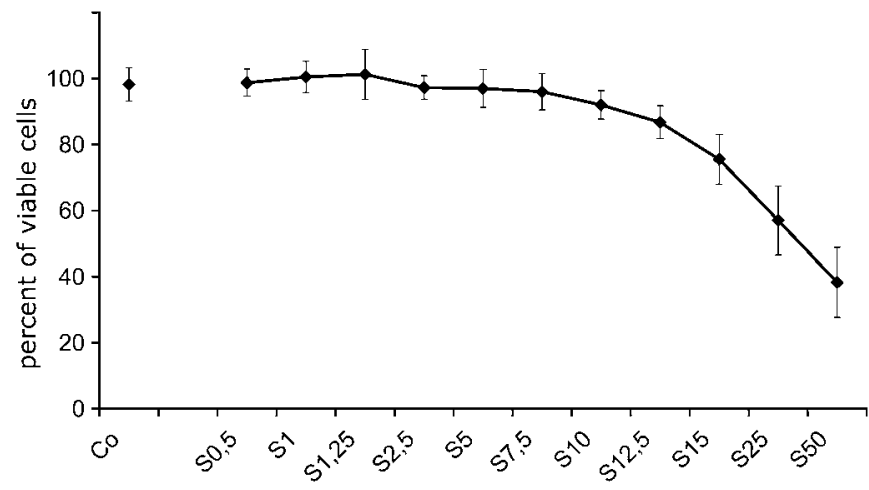

Figure 1 Viability of primary human retinal pigment epithelium cells after treatment with the various concentrations of sorafenib, measured by a colorimetric test (methylthiotetrazole). Untreated retinal pigment epithelium cells of the same passage served as controls. The results shown are the mean percentage of control cell survival from three experiments, each performed in triplicate with error bars indicating SEM. Sorafenib concentrations of up to $12.5 \mathrm{mg} / \mathrm{ml}$ showed no significant reduction in viability (Wilcoxon with $\alpha$ correction for multiple testing) compared with controls. 


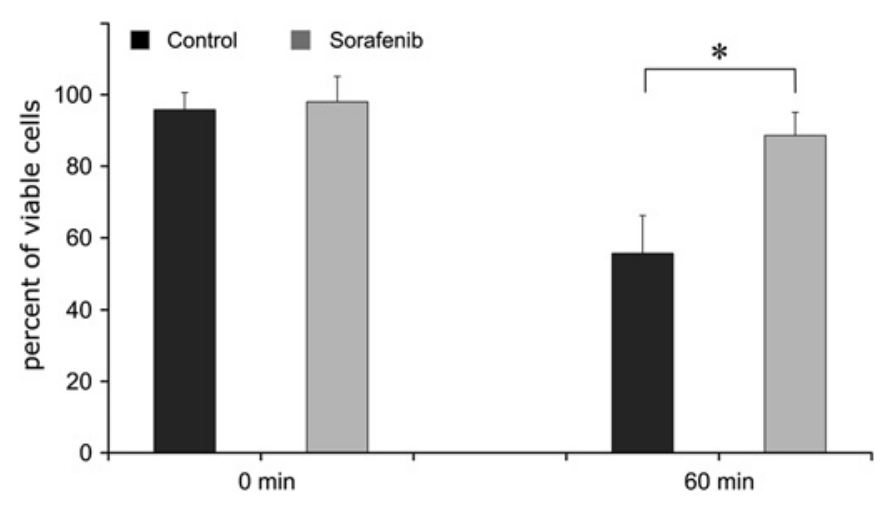

Figure 2 Viability of primary human retinal pigment epithelium cells after illumination with plain white light (black column) and after incubation with sorafenib at a concentration of $1 \mu \mathrm{g} / \mathrm{ml}$ (light grey column), as measured by a colorimetric test (methylthiotetrazole). The decrease in cellular viability was significantly reduced when cells were additionally incubated with sorafenib after $60 \mathrm{~min}$ of illumination. Error bars: SD.

increase in VEGF-A, PDGF-B and PIGF mRNA expression in RPE cells (figure 3 ). Treatment of RPE cells with sorafenib, $1 \mu \mathrm{g} / \mathrm{ml}$, directly after light exposure significantly reduced this lightinduced increase in VEGF-A, PDGF-BB and PIGF mRNA after $24 \mathrm{~h}$ (figure 3).

\section{Immunohistochemical detection of VEGF-A, PDGF-B and PIGF expression in RPE Cells}

For verification that the light-induced increase in VEGF-A, PDGF-B and PIGF mRNA transcription translates into increased protein synthesis, immunohistochemistry was performed $24 \mathrm{~h}$ after illumination.

In both untreated and non-illuminated control cells and cells that were treated with sorafenib, $1 \mu \mathrm{g} / \mathrm{ml}$, and had no illumination, only a faint staining for VEGF-A, PDGF-B and PIGF was observed (figure 4). After $60 \mathrm{~min}$ of light exposure, the expression of VEGF-A, PDGF-B and PIGF was markedly increased.

In contrast, for RPE cells that were illuminated for $60 \mathrm{~min}$ and had sorafenib at a dose of $1 \mu \mathrm{g} / \mathrm{ml}$ added directly after illumination, staining showed only a weak expression of VEGF-A, PDGF-B and PIGF, which was comparable with those cells that served as non-illuminated controls (figure 4).

\section{Detection of VEGF-A, PDGF-B and PIGF secretion of human RPE cells}

To investigate the effect of sorafenib on VEGF-A, PDGF-BB and PlGF secretion after light exposure, a quantitative detection of
VEGF-A, PDGF-BB and PIGF in cell-culture supernants was conducted using the ELISA method $24 \mathrm{~h}$ after illumination. In our experimental set-up, light exposure led to a significant increase in VEGF-A, PDGF-BB and PIGF in cultured RPE cells after 60 min of light exposure. In contrast, when cells were treated with sorafenib, $1 \mu \mathrm{g} / \mathrm{ml}$, directly after light exposure, sorafenib treatment decreased the amount of VEGF-A, PDGF-BB and PIGF significantly compared with those cells that were not treated with sorafenib after illumination (figure 5).

\section{DISCUSSION}

RPE forms the outer blood-retina barrier to facilitate selective transport between the choroidal blood vessels and the outer retina. As a phagocytic system, it is essential for the renewal of photoreceptors and plays a major role in rod and cone photoreceptor integrity. ${ }^{1}$ AMD is a disease of older people population. ${ }^{1}$ Loss and degeneration of RPE cells, particularly in the macular centre, is pathognomonic for this disease. ${ }^{1}{ }^{21}$ With advancing age, RPE cells undergo an increase in pleomorphism and accumulate metabolic debris from remnants of incomplete degradation of phagocytosed rod and cone membranes. ${ }^{1} 21$ The incomplete degradation of phagocytosed photoreceptor membranes results in a continuous increase in intracellular lipofuscin in the RPE cells over time. This lipofuscin accumulation seems to be associated with deterioration in cellular function potentially resulting in a higher sensitivity to radiation damage. ${ }^{22} 28-30$ Furthermore, the formation of drusen in Bruch membrane might compromise RPE cell function by impeding fluid transport and inducing inflammatory responses, which have been implicated in the development of AMD and $\mathrm{CNV}^{31-33}$ Once damaged, RPE cells secrete inadequate amounts of growth factors, such as VEGF, PDGF, PIGF and others. ${ }^{13-16}$ An imbalance between these growth factors in the eye potentially leads to aberrant angiogenesis resulting in the formation of dysfunctional blood vessels and $\mathrm{CNV}^{34}$

Cumulative light exposure is thought to induce proangiogenic factors in RPE cells and to promote the development of exudative AMD. ${ }^{16}{ }^{35}$ Previous studies have demonstrated that light exposure can lead to an increased production of VEGF-A in RPE cells. $^{203637}$ The reason for this could be that continuous light exposure induces sublethal cellular stress, which results in an upregulation of proangiogenic VEGF-A secretion. ${ }^{36}$

In accordance with these findings, our results clearly indicate that light exposure not only leads to an upregulation of VEGF-A but also leads to increased expression and secretion of PDGF-BB and PIGF in primary human RPE cells. a VEGF-A-RNA

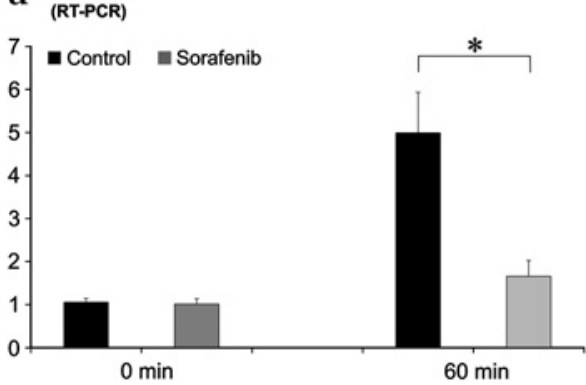

b PDGF-RNA

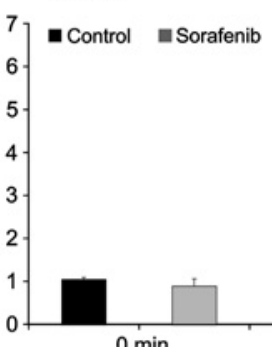

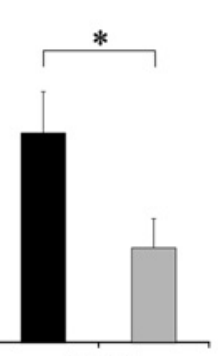

$60 \mathrm{~min}$

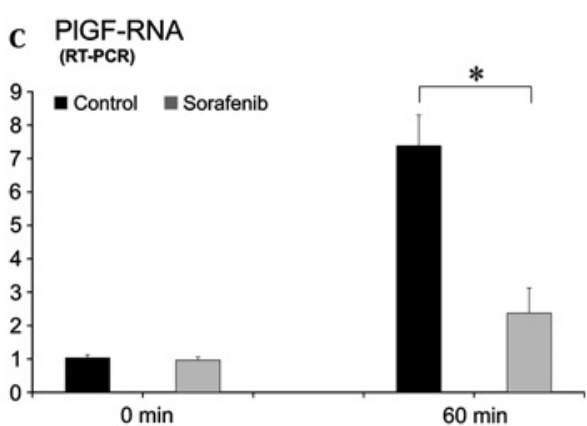

Figure 3 (A) Vascular endothelial growth factor (VEGF)-A, (B) platelet-derived growth factor (PDGF)-BB and (C) placenta growth factor (PIGF) mRNA expression of primary retinal pigment epithelium cells after illumination with plain white light (black columns) and after incubation with sorafenib at $1 \mu \mathrm{g} / \mathrm{ml}$ (light grey columns), as investigated by quantitative RT-PCR. $x$-Axis, relative ratio (RR) of VEGF-A, PDGF-BB or PIGF mRNA normalised to 18s rRNA, expressed in decimal format; $y$-axis, time of illumination. 
Figure 4 Immunohistochemical staining of vascular endothelial growth factor (VEGF)-A, platelet-derived growth factor (PDGF)-B, and placenta growth factor (PIGF) expression in retinal pigment epithelium cells. Both untreated and non-illuminated control cells and cells that were treated with sorafenib, $1 \mu \mathrm{g} / \mathrm{ml}$, and had no illumination presented only a faint staining for VEGF-A, PDGF-B and PIGF. After 60 min of light exposure, the expression of VEGF-A, PDGF-B and PIGF was markedly increased. In contrast, retinal pigment epithelium cells that were illuminated and had sorafenib added directly after illumination showed only a weak staining of VEGF-A, PDGF-B and PIGF, which was comparable with those cells that served as non-illuminated controls.
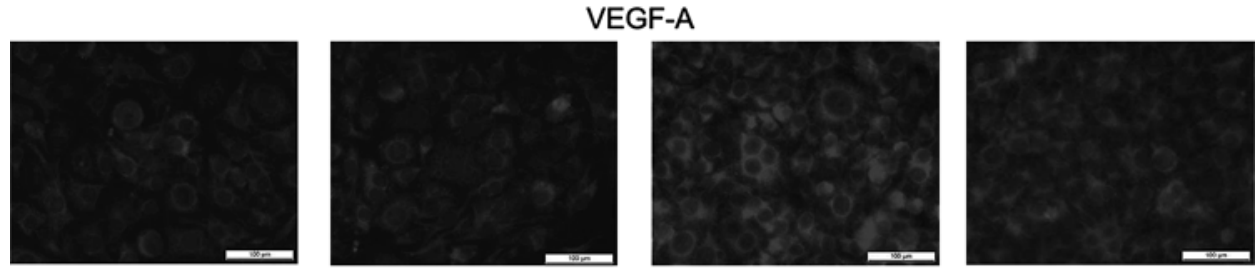

PDGF
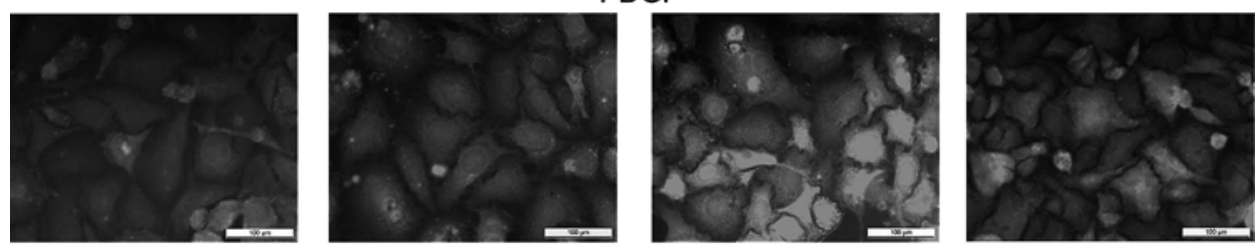

PIGF

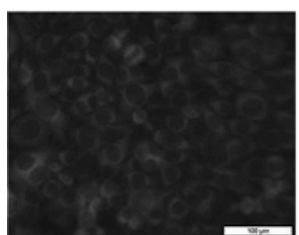

Co Omin

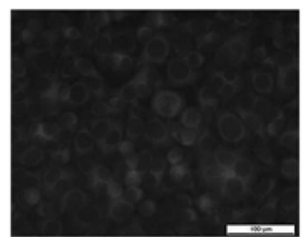

Sorafenib Omin

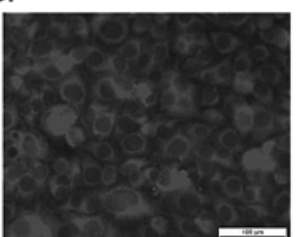

Co $60 \mathrm{~min}$

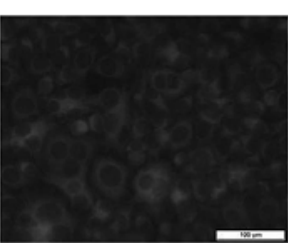

Sorafenib 60min
VEGF-A, a member of the VEGF family, is a dimeric 36-46 $\mathrm{kDa}$ glycosylated protein with a predominant role in the development of pathological angiogenesis in $\mathrm{AMD} .^{1}{ }^{7} \mathrm{~A}$ secondary important role of VEGF-A is the induction of increased vascular permeability. ${ }^{1} 671516$ In RPE cells out of the macular region of patients with AMD, VEGF-A is significantly increased, and vitreous VEGF-A levels are significantly higher in patients with $\mathrm{AMD}$ and $\mathrm{CNV}$, compared with healthy control subjects. ${ }^{38} 39$ Therefore, VEGF-A has become the main target of the currently used antiangiogenic agents in the treatment of AMD. ${ }^{8}$ However, endothelial cells and pericytes that form the structure of neovascular tissue seem not to respond to VEGF-A inhibition alone and currently used anti-VEGF agents seem to have little effect on existing capillaries. ${ }^{15}{ }^{16}$ In addition, not all attributes of $\mathrm{CNV}$ are related to vessels, but many of the structural abnormalities associated with CNV are related to fibroblasts, damage of the RPE and the remodelling of the nascent extracellular matrix. ${ }^{15} 16$

PIGF, a member of the VEGF family, induces increased vascular permeability, proliferation, chemotaxis and angiogenesis, and may act synergistically with VEGF-A in the development of CNV. ${ }^{15}{ }^{16}$ Both VEGF-A and PIGF have a recruiting effect on pericytes during angiogenesis in the maturation process of endothelial tubes, but also in the early phase of angiogenesis, where both growth factors act as an integral part of sprouting capillaries. $^{16} 4041$

PDGF-BB, another growth factor expressed by the RPE, acts as a survival factor for retinal pericytes. PDGF-BB is the key regulator of the pericyte endothelial bond and known to recruit pericytes in the development of CNV. ${ }^{15}{ }^{41-43}$ Pericytes are an important component of the choroidal neovascular complex, providing stabilisation of vessels, and are thought to limit the penetration of anti-VEGF agents. ${ }^{15}{ }^{41-43}$ In addition, PDGF is thought to have an important role in fibroplasia as a woundhealing response in CNV. ${ }^{15} 4344$

Recent studies demonstrated that combined inhibition of VEGF and PDGF enforces vessel regression by interfering with pericyte-mediated endothelial cell survival and produced inhibition and regression of corneal neovascularisation and $\mathrm{CNV}$ compared with anti-VEGF treatment alone. ${ }^{42} 43$

Therefore, a combined approach of targeting several key molecules or pathways in a complex disease state as AMD might lead to significant improvements in outcome and seems to be worth while. ${ }^{45}$

The multikinase inhibitor sorafenib was initially identified as an RAF kinase inhibitor, but it also inhibits several receptor
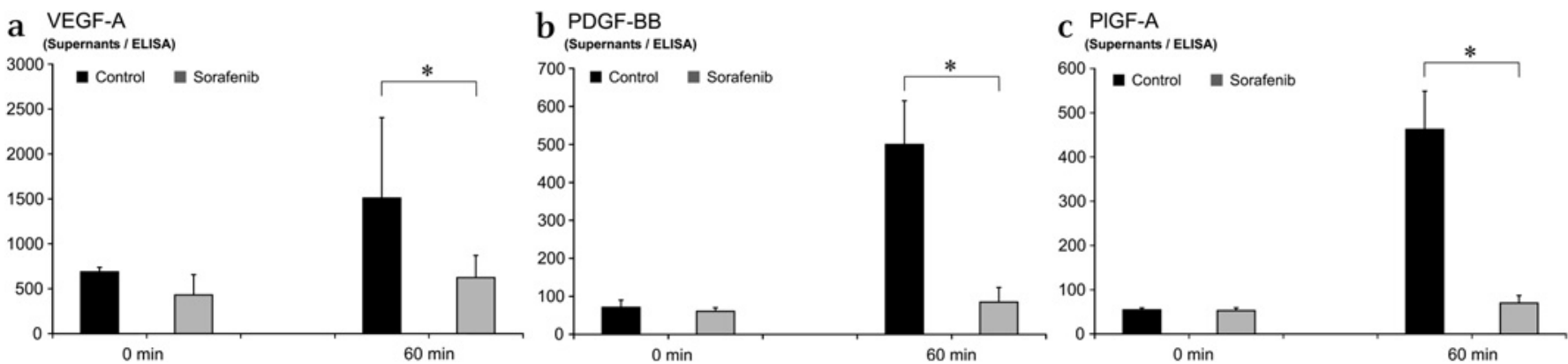

Figure 5 Inhibitory effect of sorafenib on light-induced secretion of (A) Vascular endothelial growth factor (VEGF)-A, (B) platelet-derived growth factor (PDGF)-BB and (C) placenta growth factor (PIGF), as investigated by ELISA: untreated retinal pigment epithelium cells after illumination with plain white light (black columns) and after additional treatment with sorafenib (light grey columns). Each value was normalised to a standard curve of VEGF-A, PDGF-BB or PIGF and expressed as concentration in nanograms per millilitre. Data values are means \pm SD. 
tyrosine kinases involved in angiogenesis. Sorafenib's antiproliferative and antiangiogenic efficacy seems to be derived from its blocking capability of the RAF/mitogen-activated protein (MAP)/extracellular signal-regulated kinase (ERK) kinase (MEK)/ERK (RAF/MEK/ERK) cascade and its effect on receptor tyrosine kinases, including VEGF receptor 2 (VEGFR2), VEGFR3, PDGF receptor, FLT3, Ret and c-Kit. ${ }^{17}{ }^{46-49}$ Furthermore, sorafenib interacts with hypoxia-inducible factors 1 and 2 and seems to have an influence on expression of growth factors, such as VEGF and PDGF. ${ }^{17}$ 46-48

In this study, sorafenib at a concentration of $1 \mu \mathrm{g} / \mathrm{ml}$ led to a significant reduction in the light-induced increase in expression and secretion of VEGF, PIGF, and PDGF in primary human RPE cells. Moreover, this attenuation of light-induced growth factor overexpression was accompanied by a significant improvement of light-induced decrease in RPE cell viability. One potential reason for this might be that sorafenib not only interacts with growth factor regulation but also interferes with certain proteins within the intrinsic apoptotic cascade. The exact mechanisms are not completely understood; however, it has been demonstrated for example that sorafenib inhibits the phosphorylation of the initiation factor eIF4E, which is known to regulate the translation of a large number of mRNAs, including members so the Bcl-2 family. ${ }^{17} 48$ Further research is warranted.

Sorafenib appears to be comparable with systemic anti-VEGF medications in its safety profile. ${ }^{11} 50$ The most common side effects after oral administration in patients treated for renal cell carcinoma (RCC) were dermatological symptoms such as rash or hand-foot skin reactions, diarrhoea and low-grade hypertension. Severe adverse events have been described but are rare. ${ }^{50} 51$ In addition, in our experimental set-up, sorafenib did not have a significant influence on RPE cell viability after a $24 \mathrm{~h}$ exposure up to a concentration of $12.5 \mu \mathrm{g} / \mathrm{ml}$. This is more than 10 -fold higher than the sorafenib concentration of $1 \mu \mathrm{g} / \mathrm{ml}$ effective in our experiments.

The standard dosage of sorafenib as oral treatment for RCC is $800 \mathrm{mg}$ per day. From several clinical trials, we know that after a daily dose of $800 \mathrm{mg}$ of sorafenib, plasma levels are within the range of $10 \mu \mathrm{g} / \mathrm{ml}$, after $200 \mathrm{mg}$ per day around $4.5 \mu \mathrm{g} / \mathrm{ml}$ can be reached. ${ }^{52-54}$ To date, there are no data regarding the penetration of sorafenib into ocular tissue after systemic or after topic application available, and this issue needs further investigation. However, the sorafenib concentration of $1 \mu \mathrm{g} / \mathrm{ml}$ effective in our experiments might be achievable even with a low-dose treatment.

These data provide the first evidence that sorafenib effectively interacts in human RPE cells with three important targets of AMD treatment: VEGF, PlGF and PDGF. Due to its activity against multiple targets and pathways in angiogenesis, sorafenib seems to be promising as a potential treatment for AMD. ${ }^{55}$ Another substantial difference between sorafenib to the currently used extracellular VEGF inhibitors might be that the substance potentially acts upstream and downstream in the angiogenic cascade and therefore potentially prevents transcription and protein production of growth factors in the tissue from where they are derived. ${ }^{17} 55$

Recent reports have demonstrated beneficial effects of sorafenib in AMD treatment. Kernt et al reported on a patient with occult CNV who experienced visual improvement and resolution of macular oedema under oral sorafenib treatment due to advanced RCC, where intravitreal bevacizumab treatment failed. ${ }^{19}$ Other reports describe improvement in visual acuity under low-dose sorafenib treatment alone or in combination with intravitreal ranibizumab. ${ }^{18}$
In this in vitro study sorafenib had a significant impact on growth-factor expression in the human RPE. The RPE is only one component interacting in retinal neovascular disease and not all aspects of mechanisms of action of sorafenib regarding growth factor expression and signalling are completely understood. Its additional effects on receptor tyrosine kinases and other cell types involved in the development of AMD need further investigation. However, the data presented in this in vitro study indicate that sorafenib provides properties to reduce light-induced growth factor overexpression in human RPE and, therefore, might prevent development and progression of $\mathrm{CNV}$ in vivo. Further experimental and clinical studies will have to substantiate our in vitro findings. Nevertheless, sorafenib seems to be a promising adjunctive treatment for patients with AMD.

Acknowledgements The authors thank K Obholzer for excellent technical assistance.

\section{Competing interests None.}

Patient consent Obtained.

Ethics approval Ethics approval was provided by the Ludwig-Maximilians-University Munich.

Provenance and peer review Not commissioned; externally peer reviewed.

\section{REFERENCES}

1. Ehrlich R, Harris A, Kheradiya NS, et al. Age-related macular degeneration and the aging eye. Clin Interv Aging 2008;3:473-82.

2. Cruickshanks KJ, Klein R, Klein BE. Sunlight and age-related macular degeneration. the Beaver Dam Eye Study. Arch Ophthalmol 1993;111:514-18.

3. Cruickshanks KJ, Klein R, Klein BE, et al. Sunlight and the 5-year incidence of early age-related maculopathy: the beaver dam eye study. Arch Ophthalmol 2001;119:246-50.

4. Tomany SC, Cruickshanks KJ, Klein R, et al. Sunlight and the 10-year incidence of age-related maculopathy: the beaver dam eye study. Arch Ophthalmol 2004; 122:750-7

5. Fine SL, Berger JW, Maguire MG, et al. Age-related macular degeneration. N Eng/ J Med 2000;342:483-92.

6. Jager RD, Mieler WF, Miller JW. Age-related macular degeneration. N Eng/ J Med 2008;358:2606-17.

7. Aiello LP, Pierce EA, Foley ED, et al. Suppression of retinal neovascularization in vivo by inhibition of vascular endothelial growth factor (VEGF) using soluble VEGF-receptor chimeric proteins. Proc Natl Acad Sci U S A 1995;92:10457-61.

8. Aiello LP. Targeting intraocular neovascularization and edema-one drop at a time. N Engl J Med 2008;359:967-9.

9. van Wijngaarden $\mathbf{P}$, Coster DJ, Williams KA. Inhibitors of ocular neovascularization: promises and potential problems. JAMA 2005;293:1509-13.

10. Regillo CD, Brown DM, Abraham P, et al. Randomized, double-masked, shamcontrolled trial of ranibizumab for neovascular age-related macular degeneration: PIER Study year 1. Am J Ophthalmol 2008;145:239-48.

11. Rosenfeld PJ, Brown DM, Heier JS, et al. Ranibizumab for neovascular age-related macular degeneration. N Engl J Med 2006;355:1419-31.

12. Rosenfeld PJ, Fung AE, Puliafito CA. Optical coherence tomography findings after an intravitreal injection of bevacizumab (avastin) for macular edema from central retinal vein occlusion. Ophthalmic Surg Lasers Imaging 2005;36:336-9.

13. Freyberger $\mathbf{H}$, Brocker $M$, Yakut $H$, et al. Increased levels of platelet-derived growth factor in vitreous fluid of patients with proliferative diabetic retinopathy. Exp Clin Endocrinol Diabetes 2000;108:106-9.

14. Robbins SG, Mixon RN, Wilson DJ, et al. Platelet-derived growth factor ligands and receptors immunolocalized in proliferative retinal diseases. Invest Ophthalmol Vis Sci 1994;35:3649-63.

15. Schlingemann RO. Role of growth factors and the wound healing response in age related macular degeneration. Graefes Arch Clin Exp Ophthalmol 2004;242:91-101.

16. Witmer AN, Vrensen GF, Van Noorden CJ, et al. Vascular endothelial growth factors and angiogenesis in eye disease. Prog Retin Eye Res 2003;22:1-29.

17. Wilhelm SM, Adnane L, Newell $P$, et al. Preclinical overview of sorafenib, a multikinase inhibitor that targets both Raf and VEGF and PDGF receptor tyrosine kinase signaling. Mol Cancer Ther 2008;7:3129-40.

18. Diago T, Pulido JS, Molina JR, et al. Ranibizumab combined with low-dose sorafenib for exudative age-related macular degeneration. Mayo Clin Proc 2008;83:231-4.

19. Kernt M, Staehler M, Stief C, et al. Resolution of macular oedema in occult choroidal neovascularization under oral Sorafenib treatment. Acta Ophthalmol 2008;86:456-8.

20. Kernt M, Neubauer AS, Liegl R, et al. Cytoprotective effects of a blue light-filtering intraocular lens on human retinal pigment epithelium by reducing phototoxic effects on vascular endothelial growth factor-alpha, Bax, and Bcl-2 expression. J Cataract Refract Surg 2009;35:354-62. 
21. Algvere PV, Marshall J, Seregard S. Age-related maculopathy and the impact of blue light hazard. Acta Ophthalmol Scand 2006;84:4-15.

22. Algvere PV, Seregard S. Age-related maculopathy: pathogenetic features and new treatment modalities. Acta Ophthalmol Scand 2002;80:136-43.

23. Holz FG, Pauleikhoff $D$, Klein $\mathrm{R}$, et al. Pathogenesis of lesions in late age-related macular disease. Am J Ophthalmol 2004:137:504-10.

24. Barishak YR. In vitro behaviour of the pigmented cells of the retina and uvea of the adult human eye. Acta Ophthalmol (Copenh) 1960;38:339-46.

25. Flood MT, Gouras P. Kieldbye H. Growth characteristics and ultrastructure of human retinal pigment epithelium in vitro. Invest Ophthalmol Vis Sci 1980;19:1309-20.

26. Nilsson SE, Sundelin SP, Wihlmark U, et al. Aging of cultured retinal pigment epithelial cells: oxidative reactions, lipofuscin formation and blue light damage. Doc Ophthalmol 2003;106:13-16.

27. Mosmann T. Rapid colorimetric assay for cellular growth and survival: application to proliferation and cytotoxicity assays. J Immunol Methods 1983;65:55-63.

28. Roth F, Bindewald A, Holz FG. Keypathophysiologic pathways in age-related macular disease. Graefes Arch Clin Exp Ophthalmol 2004;242:710-16.

29. Holz FG, Bellmann C, Margaritidis M, et al. Patterns of increased in vivo fundus autofluorescence in the junctional zone of geographic atrophy of the retinal pigment epithelium associated with age-related macular degeneration. Graefes Arch Clin Exp Ophthalmol 1999;237:145-52

30. Schutt F, Bergmann M, Holz FG, et al. Isolation of intact lysosomes from human RPE cells and effects of A2-E on the integrity of the lysosomal and other cellular membranes. Graefes Arch Clin Exp Ophthalmol 2002;240:983-8.

31. Hageman GS, Luthert PJ, Victor Chong NH, et al. An integrated hypothesis that considers drusen as biomarkers of immune-mediated processes at the RPE-Bruch's membrane interface in aging and age-related macular degeneration. Prog Retin Eye Res 2001:20:705-32.

32. Starita C, Hussain AA, Patmore A, et al. Localization of the site of major resistance to fluid transport in Bruch's membrane. Invest Ophthalmol Vis Sci 1997;38:762-7.

33. Moshfeghi DM, Blumenkranz MS. Role of genetic factors and inflammation in agerelated macular degeneration. Retina 2007;27:269-75.

34. Bhutto IA, McLeod DS, Hasegawa T, et al. Pigment epithelium-derived factor (PEDF) and vascular endothelial growth factor (VEGF) in aged human choroid and eyes with age-related macular degeneration. Exp Eye Res 2006;82:99-110.

35. Zhou J, Cai B, Jang YP, et al. Mechanisms for the induction of HNE- MDA- and AGEadducts, RAGE and VEGF in retinal pigment epithelial cells. Exp Eye Res 2005;80:567-80.

36. Yanagi $\mathbf{Y}$, Inoue $Y$, Iriyama $A$, et al. Effects of yellow intraocular lenses on lightinduced upregulation of vascular endothelial growth factor. J Cataract Refract Surg 2006;32:1540-4.

37. Kernt M, Hirneiss C, Neubauer AS, et al. Protective effect of blue light-absorbing IOLs on the human retinal pigment epithelium. Ophthalmologe $2010 \mathrm{Feb} ; 107: 150-7$.

38. Kliffen M, van der Schaft TL, Mooy CM, et al. Morphologic changes in age-related maculopathy. Microsc Res Tech 1997:36:106-22.
39. Wells JA, Murthy R, Chibber R, et al. Levels of vascular endothelial growth factor are elevated in the vitreous of patients with subretinal neovascularisation. $\mathrm{Br} J$ Ophthalmol 1996;80:363-6.

40. Crocker DJ, Murad TM, Geer JC. Role of the pericyte in wound healing. An ultrastructural study. Exp Mol Pathol 1970;13:51-65.

41. Schlingemann RO, Oosterwijk E, Wesseling $P$, et al. Aminopeptidase a is a constituent of activated pericytes in angiogenesis. $J$ Pathol 1996;179:436-42.

42. Erber $\mathbf{R}$, Thurnher $A$, Katsen AD, et al. Combined inhibition of VEGF and PDGF signaling enforces tumor vessel regression by interfering with pericyte-mediated endothelial cell survival mechanisms. Faseb J 2004;18:338-40.

43. Jo N, Mailhos C, Ju M, et al. Inhibition of platelet-derived growth factor B signaling enhances the efficacy of anti-vascular endothelial growth factor therapy in multiple models of ocular neovascularization. Am J Pathol 2006;168:2036-53.

44. Werner S, Grose R. Regulation of wound healing by growth factors and cytokines Physiol Rev 2003:83:835-70.

45. Spaide RF. Rationale for combination therapy in age-related macular degeneration Retina 2009;29(6 Suppl):S5-7.

46. Adnane L, Trail PA, Taylor I, et al. Sorafenib (BAY 43-9006, Nexavar), a dual-action inhibitor that targets RAF/MEK/ERK pathway in tumor cells and tyrosine kinases VEGFR/PDGFR in tumor vasculature. Methods Enzymol 2006; 407:597-612

47. Liu L, Cao Y, Chen C, et al. Sorafenib blocks the RAF/MEK/ERK pathway, inhibits tumor angiogenesis, and induces tumor cell apoptosis in hepatocellular carcinoma model PLC/PRF/5. Cancer Res 2006;66:11851-8.

48. Wilhelm SM, Carter C, Tang L, et al. BAY 43-9006 exhibits broad spectrum oral antitumor activity and targets the RAF/MEK/ERK pathway and receptor tyrosine kinases involved in tumor progression and angiogenesis. Cancer Res 2004:64:7099-109.

49. Carlomagno F, Anaganti S, Guida T, et al. BAY 43-9006 inhibition of oncogenic RET mutants. J Natl Cancer Inst 2006;98:326-34.

50. Escudier B, Eisen T, Stadler WM, et al. Sorafenib in advanced clear-cell renal-cell carcinoma. N Engl J Med 2007;356:125-34.

51. Ratain MJ, Eisen T, Stadler WM, et al. Phase II placebo-controlled randomized discontinuation trial of sorafenib in patients with metastatic renal cell carcinoma. J Clin Oncol 2006;24:2505-12.

52. Abou-Alfa GK, Schwartz L, Ricci S, et al. Phase II study of sorafenib in patients with advanced hepatocellular carcinoma. J Clin Oncol 2006;24:4293-300.

53. Houben R, Voigt $H$, Noelke $C$, et al. MAPK-independent impairment of T-cell responses by the multikinase inhibitor sorafenib. Mol Cancer Ther 2009;8:433-40.

54. Kupsch P, Henning BF, Passarge $K$, et al. Results of a phase I trial of sorafenib (BAY 43-9006) in combination with oxaliplatin in patients with refractory solid tumors, including colorectal cancer. Clin Colorectal Cancer 2005;5:188-96.

55. Peyman GA, Fiscella R, Conway M. Combination angiostatic therapies: current status. Retina 2009:29(6 Suppl):S18-20. 


\section{Sorafenib prevents human retinal pigment epithelium cells from light-induced overexpression of VEGF, PDGF and PIGF}

M Kernt, A S Neubauer, R G Liegl, et al.

Br J Ophthalmol 2010 94: 1533-1539

doi: 10.1136/bjo.2010.182162

Updated information and services can be found at:

http://bjo.bmj.com/content/94/11/1533.full.html

These include:

References This article cites 55 articles, 14 of which can be accessed free at: http://bjo.bmj.com/content/94/11/1533.full.html\#ref-list-1

Article cited in:

http://bjo.bmj.com/content/94/11/1533.full.html\#related-urls

Email alerting Receive free email alerts when new articles cite this article. Sign up in service the box at the top right corner of the online article.

Topic Articles on similar topics can be found in the following collections Collections

$$
\text { Retina (1328 articles) }
$$

Notes

To request permissions go to:

http://group.bmj.com/group/rights-licensing/permissions

To order reprints go to:

http://journals.bmj.com/cgi/reprintform

To subscribe to BMJ go to:

http://group.bmj.com/subscribe/ 